\title{
Possible Function of Norharmane in Egg-Laying by Ergatoids and Nymphoids of the Lower Termite, Reticulitermes speratus (Kolbe)
}

\author{
Shuji Itakura*, Satoshi Kawabata, Hiromi Tanaka and Akio Enoki \\ Department of Applied Biological Chemistry, Kinki University, Naka-Machi, Nara, 631-8505, Japan
}

\begin{abstract}
The aromatic $\beta$-carboline norharmane, which is located in the fat body of Reticulitermes speratus, stimulated the activity of juvenile hormone epoxide hydrolase (JHEH) of larva, ergatoid, and nymphoid homogenates. JHEH activity of ergatoid (16.67 $\pm 1.30 \mu \mathrm{U} /$ termite $)$ and nymphoid $(20.94 \pm 1.64 \mu \mathrm{U} /$ termite $)$ homogenates fortified with $0.1 \mathrm{mM}$ norharmane was significantly higher than that of ergatoid $(9.84 \pm 1.69 \mu$ U/termite) and nymphoid $(16.99 \pm 0.60$ $\mu \mathrm{U} /$ termite) homogenates to which no norharmane was added. Egg-laying by ergatoids and nymphoids, which ingested norharmane by feeding on norharmane-treated filter paper, was observed in 3 weeks. During rearing on filter paper without norharmane, egg-laying by ergatoids was observed in 5 weeks, whereas no egg-laying by nymphoids was observed throughout the incubation period of 8 weeks. Norharmane seems to be involved in egg development of ergatoids and nymphoids of $R$. speratus.
\end{abstract}

\section{INTRODUCTION}

Termite caste differentiation is a post-embryonic developmental process. Caste differentiation and development in the genus Reticulitermes can follow either apterous or imaginal pathways [1]. The apterous pathway is the line of workers that comprises five instars, and the imaginal pathway is the line of nymphs that comprises six instars and is distinguished from other castes by the possession of wing buds [2]. The initial separation of two developmental lines occurs after two larval instars. Nymphs have two developmental potentials: differentiation into adult alates that establish a new colony as primary reproductives or differentiation into nymphoids that supplement the reproductive capacity within colonies. Workers have three developmental potentials: status quo molts remaining as workers, differentiation into presoldiers (followed immediately by molting into soldiers), or differentiation into ergatoids that assume identical functions as nymphoids. Caste differentiation in termites is strongly influenced by changes in juvenile hormone $(\mathrm{JH})$ titer [3]. High titers of $\mathrm{JH}$ lead to differentiation of workers to presoldiers [4], whereas low titers result in status quo worker-to-worker molts [1]. JH plays a key role in egg development as well as caste differentiation. In Reticulitermes flavipes (Kollar), egg development is related to rates of $\mathrm{JH}$ synthesis [5]. JH regulation of ovarian development was also demonstrated in Zootermopsis nevadensis (Hagen): application of $\mathrm{JH}$ analogue to nymphs resulted in the maturation of ovarian development in soldier-alate intercastes [6].

The primary routes of $\mathrm{JH}$ metabolism in insects are ester hydrolysis to $\mathrm{JH}$ acid and epoxide hydration to $\mathrm{JH}$ diol by $\mathrm{JH}$ esterase (JHE) and $\mathrm{JH}$ epoxide hydrolase (JHEH), respectively. This is the case for JH metabolism in Reticulitermes speratus (Kolbe), because metabolites of JH III by termite homogenates were JH III acid and JH III diol and both JHE and JHEH activities were detected in termite homogenates [7]. Norharmane, which is a fluorescent chromophore

*Address correspondence to this author at the Department of Applied Biological Chemistry, Kinki University, Naka-Machi, Nara, 631-8505, Japan; E-mail: itakura@nara.kindai.ac.jp located in the hemolymph [8] and in the fat body [7] of $R e$ ticulitermes termites, has antimicrobial activity against the entomopathogenic fungus Matarhizium anisopliae [9] and autophototoxic activity in $R$. flavipes, Reticulitermes tibialis Banks, and Reticulitermes virginicus (Banks) [8, 10]. We found that norharmane has another novel function of stimulation of JHEH activity of enzyme extract from ergatoids of $R$. speratus [7]. The elevated JHEH activity stimulated by norharmane should accelerate $\mathrm{JH}$ metabolism in $R$. speratus. However, a boost in JHEH activity by norharmane was not observed in enzyme extract from workers of $R$. speratus. The effect of norharmane on JHEH activity could vary from caste to caste in $R$. speratus. In this study, we have attempted to obtain evidence that norharmane is involved in caste differentiation or egg development in $R$. speratus. This has been done by assessing the effect of norharmane on the JHEH activity of larvae, nymphs, soldiers, workers, ergatoids, and nymphoids, and by observing egg-laying by ergatoids and nymphoids fed on a diet of filter paper that included norharmane.

\section{MATERIALS AND METHODS}

\section{Termites}

$R$. speratus individuals were collected in April 2007 from a wild colony located in an infested wood in the Wakayama Prefecture, Japan, and were maintained in the laboratory at $26^{\circ} \mathrm{C}$ with their nest materials and with blocks of Pinus densiflora Sieb. et Zucc as the food source. Non-reproductives, larvae, nymphs, workers, soldiers, and neotenic reproductives (nymphoids differentiated from nymphs and ergatoids from workers as described by Miyata et al. [11]) were collected from the colony maintained in the laboratory in June, July and August 2007. Ergatoids from the June collection were used to examine the effect of norharmane on egg- laying.

\section{Chemicals}

Norharmane was purchased from Sigma-Aldrich (St. Louis, MO, USA). Labeled JH III (647.5 GBq/mmol, ${ }^{3} \mathrm{H}$ at C-10) was obtained from Perkin-Elmer Life Science (Bos- 
ton, MA, USA). The radiochemical purity was $>99 \%$. Unlabeled JH III (Sigma-Aldrich) was mixed with the labeled JH III to give a final substrate concentration of $0.5 \mathrm{mM}$ in ethanol having $8000 \mathrm{cpm} / \mu \mathrm{l}$. 3-Octylthio-1,1,1-trifluoro-2propanone (OTFP) was synthesized as previously described [7]. OTFP was dissolved in ethanol to give a final concentration of $10 \mathrm{mM}$.

\section{Assay of JHEH}

Twenty-four larvae, 12 nymphs, soldiers and workers, eight ergatoids and nymphoids were homogenized, respectively, in $1.2 \mathrm{ml}$ of sodium phosphate buffer $(\mathrm{pH} \mathrm{7.4,} 200$ $\mathrm{mM}$ ), containing $0.01 \%$ phenylthiourea, and $10 \%$ sucrose at $0-4{ }^{\circ} \mathrm{C}$ [12]. Initial JHEH activity of each homogenate ranged from $\sim 50$ to $100 \mu \mathrm{U} / \mathrm{ml}$. The activity of JHEH in each extract of $R$. speratus was determined by a partition assay following $\mathrm{JH}$ diol produced from ${ }^{3} \mathrm{H}$-labeled JH III substrate [12] in the presence of OTFP that is a selective inhibitor of JHE [13]. Each enzyme extract $(100 \mu \mathrm{l})$ was pre-incubated for $10 \mathrm{~min}$ at $30^{\circ} \mathrm{C}$ with $1 \mu \mathrm{l}$ of $10 \mathrm{mM}$ OTFP, which depressed the JHE activity of $R$. speratus to $\sim 10 \%$ (the efficacy of inhibition was $89.0 \pm 2.8 \%$ ) as well as JHEH activity to $\sim 77 \%$ (the efficacy of inhibition was $23.0 \pm 3.9 \%$ ) [7]. Reactions were initiated by the addition of $1 \mu \mathrm{l}$ of ${ }^{3} \mathrm{H}$-labeled $\mathrm{JH}$ III substrate $(0.5 \mathrm{mM}, 8000 \mathrm{cpm})$. After incubation for 15 $\mathrm{min}$ at $30^{\circ} \mathrm{C}$, methanol $(300 \mu \mathrm{l})$ and iso-octane $(250 \mu \mathrm{l})$ were added to the samples in an ice bath. Each sample was vigorously vortexed, followed by centrifugation at $1000 \mathrm{~g}$ for 5 min. Aliquots of $100 \mu \mathrm{l}$ were recovered from the top and bottom phases and the radioactivity of each fraction was analyzed using a liquid scintillation counter (LSC-5100, Aloka, Tokyo, Japan). The volumes of iso-octane (top phase) and aqueous methanol (bottom phase) were $250 \mu \mathrm{l}$ and 400 $\mu \mathrm{l}$, respectively, and the percentage $\mathrm{JH}$ III in the aqueous methanol phase was $32.6 \pm 0.6(n=8)$. The percentage metabolism was calculated using the following formula:

$\%$ metabolism $=\left[\left(\mathrm{CPM}_{\mathrm{b}} \times 4.0\right)-\left(\mathrm{CPM}_{\mathrm{t}} \times 2.5\right)(32.6 / 67.4)\right] /$ $\left[\left(\mathrm{CPM}_{\mathrm{b}} \times 4.0\right)+\left(\mathrm{CPM}_{\mathrm{t}} \times 2.5\right)\right] \times 100$

$\mathrm{CPM}_{\mathrm{t}}$ : background corrected cpm for the top fraction

$\mathrm{CPM}_{\mathrm{b}}$ : background corrected cpm for the bottom fraction.

$\mathrm{JH}$ metabolism was calculated from the incubation time and the product of the decimal percentage metabolism and the moles of JH III per assay $(0.5 \mathrm{nmol})$. One unit of JHEH activity is defined as the amount of enzyme that metabolizes $1 \mu \mathrm{mol}$ of $\mathrm{JH}$ into $\mathrm{JH}$ diol per minute.

\section{Effect of Norharmane on JHEH Activity}

The determination of JHEH activity was carried out as described above, except that $1 \mu \mathrm{l}$ of 1 and $10 \mathrm{mM}$ norharmane in ethanol, or $1 \mu \mathrm{l}$ of ethanol (control), was added to each enzyme extract before pre-incubation. Final concentrations of 0.01 and $0.1 \mathrm{mM}$ norharmane were determined on the basis of the fact that $0.1 \mathrm{mM}$ norharmane stimulated the JHEH activity of ergatoids of $R$. speratus more effectively than $1 \mathrm{mM}$ norharmane and that 3-5 $\mathrm{mM}$ norharmane inhibited the JHEH activity of workers of $R$. speratus [7].

\section{Termite Feeding}

A hole was drilled in two cylindrical containers (polystyrene, $50 \mathrm{~mm}$ in diameter, $60 \mathrm{~mm}$ in height, Yamayu, Osaka,
Japan) and they were joined by Tygon tubing, $7 \mathrm{~cm}$ in length (2.4 $\mathrm{mm}$ id, $5.5 \mathrm{~mm}$ od, Saint-Gobain Performance Plastics Corporation, Akron, OH, USA). A mixture of $\sim 10 \mathrm{ml}$ of vermiculite, $\sim 10 \mathrm{ml}$ of sand, and $\sim 10 \mathrm{ml}$ of distilled water was poured into one of the containers. A filter paper $(70 \mathrm{~mm}$, Advantec Toyo Kaisha, Tokyo, Japan) was placed on the bottom of the other container as food for the termites. Onehundred workers for observation of workers'development, five ergatoids plus one-hundred eighty workers and five nymphoids plus one-hundred eighty workers for observation of egg-laying were, respectively, placed in separate containers with a mixture of vermiculite and sand. After each container had been covered with a polyethylene sheet (Aisaika®, $70 \mathrm{~mm}$ x $70 \mathrm{~mm}$, Nipro, Osaka, Japan), vented lids were placed on both the containers with the filter paper and the mixture of vermiculite and sand. Workers' development was observed every 3 weeks for 9 weeks by inverting both containers $(n=5)$ to remove all materials and termites from both containers. For observation of egg-laying, other three sets of containers had been prepared for ergatoids and nymphoids, respectively, as described previously. Once a container with a mixture of vermiculite and sand, and containing a small nest, had been dismantled, it was impossible to assess the egg production by ergatoids and nymphoids in the following weeks. Egg-laying by ergatoids $(n=3)$ and nymphoids $(n=3)$ on the surface of a small nest of vermiculite and sand in a container was, therefore, observed using a SZ260 stereoscopic zoom microscope (Olympus, Tokyo, Japan) every week for 6 to 8 weeks by opening the lids of the containers followed by removing the polyethylene sheets. The images were captured using a Fuji FinePix 600Z digital camera (Fujifilm, Tokyo, Japan). All experiments were carried out at $26^{\circ} \mathrm{C}$.

\section{Effect of Norharmane on Workers' Development and Egg-Laying by Ergatoids and Nymphoids}

Rearing of workers for observation of workers'development, of ergatoids plus workers and nymphoids plus workers for observation of egg-laying was carried out as described above, except that $0.1 \%$ norharmane in methanol was added to a filter paper to a final concentration of 0.05 or $0.10 \%(\mathrm{w} / \mathrm{w})$.

\section{RESULTS \\ JHEH Activity}

The primary routes of $\mathrm{JH}$ metabolism in homogenates of $R$. speratus are epoxide hydration and ester hydrolysis. Addition of the selective JHE inhibitor OTFP to termite homogenates enabled assay of JHEH, though $\sim 10 \%$ of JHE activity remained in the homogenates as described above. JHEH activity varied from caste to caste (Table 1). In the absence of additional norharmane, JHEH activity of nymphoid homogenate was significantly greater than that of larva, nymph, soldier, worker, and ergatoid homogenates, whereas JHEH activity of ergatoid homogenate was not significantly different from that of nymph, soldier, and worker homogenates $(P>0.05)$. Similarly, in the absence of additional norharmane, JHEH activity of nymph homogenate was significantly greater than that of larva and soldier homogenates, whereas JHEH activity of worker homogenate was significantly greater than that of larva homogenate $(\mathrm{P}>0.05)$. Addition of $1 \mathrm{mM}$ norharmane to termite homogenates sig- 
Table 1. JHEH Activity $\pm \operatorname{SEM}(\mu \mathrm{U} / \text { termite })^{\mathrm{a}, \mathrm{b}}$ of $R$. speratus

\begin{tabular}{|c|c|c|c|}
\hline \multirow{2}{*}{ Instar } & \multicolumn{3}{|c|}{ Concentration of Norharmane (mM) } \\
\cline { 2 - 4 } & $\mathbf{0}$ & $\mathbf{0 . 0 1}$ & $\mathbf{0 . 1}$ \\
\hline \hline Larva & $2.31 \pm 0.11 \mathrm{a}$ & $2.32 \pm 0.36 \mathrm{a}, \mathrm{b}$ & $3.04 \pm 0.13 \mathrm{~b}$ \\
\hline Nymph & $9.64 \pm 0.60 \mathrm{a}$ & $9.44 \pm 0.67 \mathrm{a}$ & $5.77 \pm 0.79 \mathrm{a}$ \\
\hline Soldier & $5.90 \pm 0.70 \mathrm{a}$ & $5.55 \pm 0.28 \mathrm{a}$ & $10.36 \pm 1.03 \mathrm{a}$ \\
\hline Worker & $8.19 \pm 0.81 \mathrm{a}$ & $9.96 \pm 0.63 \mathrm{a}$ & $16.67 \pm 1.30 \mathrm{~b}$ \\
\hline Ergatoid & $9.84 \pm 1.69 \mathrm{a}$ & $14.43 \pm 1.05 \mathrm{a}$ & $20.94 \pm 1.64 \mathrm{~b}$ \\
\hline Nymphoid & $16.99 \pm 0.60 \mathrm{a}$ & $18.38 \pm 2.16 \mathrm{a}, \mathrm{b}$ & \\
\hline
\end{tabular}

${ }^{\mathrm{a}}$ One unit of JHEH activity is defined as the amount of enzyme that metabolizes $1 \mu \mathrm{mol}$ of JH into JH diol per minute.

${ }^{\mathrm{b}}$ Means followed by the same letter within each row (instar) are not significantly different from each other, $\mathrm{P}>0.05$. Each measurement was replicated four times $(n=4)$.

Table 2. Effect of Norharmane on Ergatoid Emergence from Workers

\begin{tabular}{|c|c|c|c|}
\hline \multirow{2}{*}{ Norharmane (\%) } & \multicolumn{3}{|c|}{ Ergatoids from 100 workers (termites) $^{\mathrm{a}}$} \\
\cline { 2 - 4 } & $\mathbf{3}$ & $\mathbf{6}$ & Incubation period (weeks) $^{\mathbf{9}}$ \\
\cline { 2 - 4 } & $0 \mathrm{a}$ & $0.20 \pm 0.20 \mathrm{a}$ & $2.00 \pm 0.32 \mathrm{~b}$ \\
\hline \hline 0 & $0 \mathrm{a}$ & $0.40 \pm 0.24 \mathrm{a}$ & $0.80 \pm 0.37 \mathrm{a}, \mathrm{b}$ \\
\hline 0.05 & $0 \mathrm{a}$ & $0.40 \pm 0.24 \mathrm{a}, \mathrm{c}$ & $1.40 \pm 0.68 \mathrm{~b}, \mathrm{c}$ \\
\hline
\end{tabular}

${ }^{\mathrm{a}}$ Means followed by the same letter within each row and column, except for the column of 3 weeks, are not significantly different from each other, $\mathrm{P}>0.05(n=5)$.

nificantly promoted JHEH activity in larva, ergatoid, and nymphoid homogenates (Table 1). However, the difference in JHEH activity between homogenates to which 0 and 0.01 $\mathrm{mM}$ norharmane had been added was not significant in all castes (larvae, nymph, soldier, worker, ergatoid, and nymphoid) examined in the present study.

\section{Effect of Norharmane on Worker Development}

Two ergatoids emerged from 100 workers which were fed filter paper without norharmane for 9 weeks (Table 2). The difference in the number of ergatoids emerging from workers which were fed filter papers with $0,0.05$, and $0.10 \%$ norharmane for 9 weeks was not significant, nor was the difference in numbers fed norharmane for 6 weeks.

\section{Effect of Norharmane on Egg-Laying by Neotenics}

Ergatoids which were fed filter paper without norharmane laid eggs in 5 weeks as shown in Fig. (1). Ergatoids which were fed filter paper with $0.05 \%$ norharmane laid eggs (figure not shown) in 3 weeks, whereas no egg was observed in containers in which ergatoids were fed filter paper with $0.10 \%$ norharmane (Table 3). Ergatoids which were kept with workers had a tendency to avoid norharmane at higher concentration, because mass loss of filter papers with $0.10 \%$ norharmane fed to ergatoids and workers was significantly smaller than that of filter papers without norharmane. Eggs were observed in a container in which nymphoids were fed filter paper with $0.10 \%$ norharmane in 3 weeks (Fig. 2) and 5-9 weeks, though no egg was observed at 4 weeks.

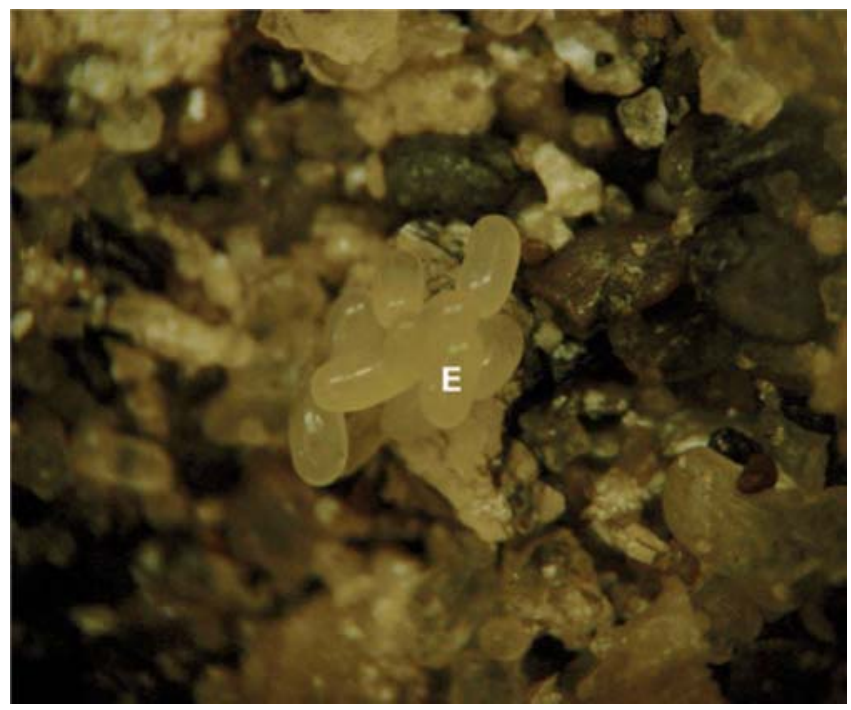

Fig. (1). Eggs laid by ergatoids in 5 weeks which were fed filter paper without norharmane. E, Egg.

A newly hatched larva was observed in a container with filter paper with $0.10 \%$ norharmane in 7 weeks (Fig. 3). No egg was observed in containers in which nymphoids were fed filter paper with 0 and $0.05 \%$ norharmane throughout 8 weeks. Nymphoids which were reared with workers did not show avoidance of norharmane, because the difference in mass loss of filter papers fed to nymphoids and workers was not significant among filter papers with $0,0.05$, and $0.10 \%$ norharmane (Table 4). 
Table 3. Effect of Norharmane on Egg-Laying by Ergatoid

\begin{tabular}{|c|c|c|c|c|c|c|c|}
\hline Norharmane (\%) & \multicolumn{6}{|c|}{ Incubation period (weeks) } & Mass loss of filter paper $(\mathrm{mg})^{\mathrm{a}}$ \\
\hline 0 & N.O. ${ }^{b}$ & N.O. & N.O. & N.O. & $8.6 \pm 4.4$ & N.O. & $205.7 \pm 17.1 \mathrm{a}$ \\
\hline 0.05 & N.O. & N.O. & $4.0 \pm 4.0$ & $3.3 \pm 3.3$ & N.O. & N.O. & $137.2 \pm 20.0 \mathrm{a}, \mathrm{b}$ \\
\hline
\end{tabular}

${ }^{\mathrm{a}}$ Means followed by the same letter are not significantly different from each other, $\mathrm{P}>0.05(n=3)$.

${ }^{\mathrm{b}}$ Not observed.

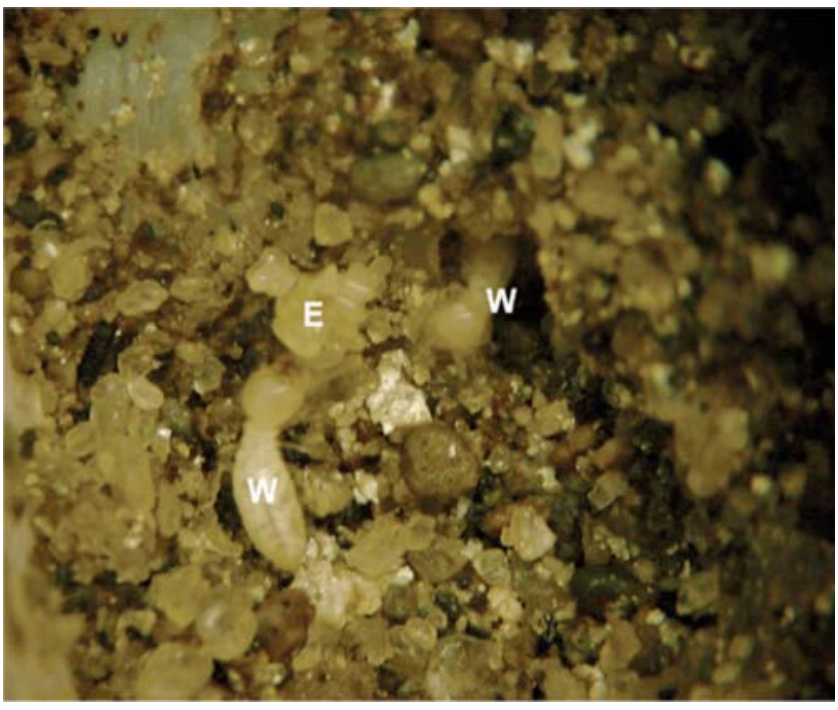

Fig. (2). Eggs laid by nymphoids in 3 weeks which were fed filter paper with $0.10 \%$ norharmane. E, Egg. W, Worker.

\section{DISCUSSION}

The present study confirmed that $0.1 \mathrm{mM}$ norharmane significantly promoted JHEH activity of larva, ergatoid, and nymphoid homogenates of $R$. speratus (Table $\mathbf{1}$ ). However, stimulation of JHEH activity was caste specific and the difference in JHEH activity between homogenates incubated with 0 and $0.1 \mathrm{mM}$ norharmane was not significant in nymph, soldier, and worker homogenates. JHEH activity in nymph, soldier, and worker homogenates as well as in larva, ergatoid, and nymphoid homogenates was somewhat in- creased because the effect of OTFP to inhibit JHE activity in homogenates of $R$. speratus was $\sim 90 \%$ and thus $\sim 10 \%$ of JHE activity remained in the termite homogenates. In nymph, soldier, and worker homogenates, seeming JHEH activity from the remaining JHE activity could account for most of the JHEH activity listed in Table $\mathbf{1}$ and thus norharmane did not significantly affect JHEH activity in these homogenates.

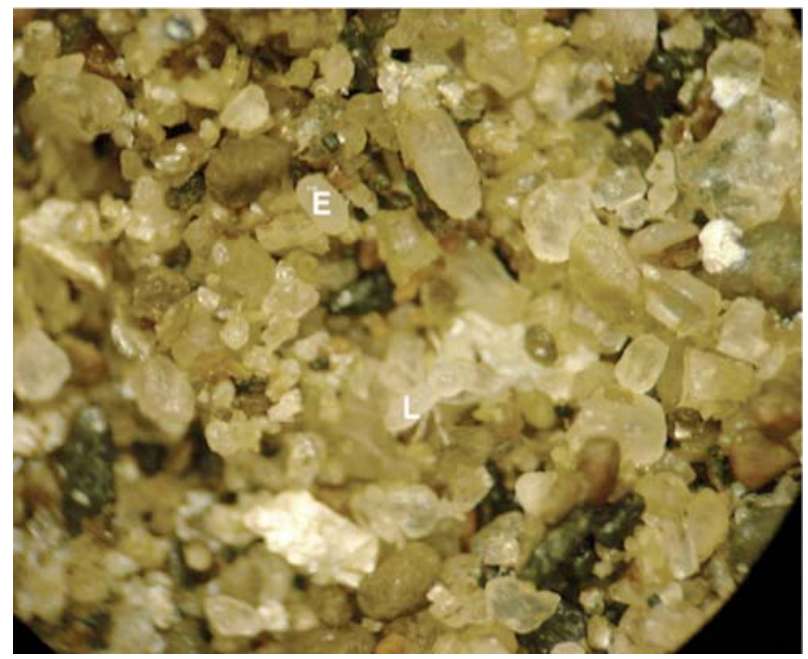

Fig. (3). Larva hatched out in 7 weeks from an egg laid by nymphoids which were fed filter paper with $0.10 \%$ norharmane. E, Egg. L, Larva.

Norharmane failed to increase JHEH activity in worker homogenates as mentioned above. This could mean that the $\mathrm{JH}$ titer in worker caste termites which were fed filter paper

Table 4. Effect of Norharmane on Egg-Laying by Nymphoid

\begin{tabular}{|c|c|c|c|c|c|c|c|c|c|}
\hline Norharmane (\%) & \multicolumn{8}{|c|}{ Egg-laying by 5 nymphoids (eggs) } & Mass loss of filter paper $(\mathbf{m g})^{2}$ \\
\hline 0 & N.O. ${ }^{b}$ & N.O. & N.O. & N.O. & N.O. & N.O. & N.O. & N.O. & $227.3 \pm 5.3 \mathrm{a}$ \\
\hline 0.05 & N.O. & N.O. & N.O. & N.O. & N.O. & N.O. & N.O. & N.O. & $169.1 \pm 29.7 \mathrm{a}$ \\
\hline
\end{tabular}

${ }^{\mathrm{a}}$ Means followed by the same letter are not significantly different from each other, $\mathrm{P}>0.05(n=3)$.

${ }^{b}$ Not observed. ${ }^{c}$ One larva emerged at 7 weeks. Any larva was not observed at 8 weeks. 
with norharmane was maintained at a steady level. Indeed, the difference among numbers of ergatoids emerging from workers which were fed filter papers with $0,0.05$, and 0.10 $\mathrm{mM}$ norharmane was not significant (Table 2). The results were consistent with the description that workers of Reticulitermes termites molt to workers (status quo) in low titers of $\mathrm{JH}$ [1]. In the present study ergatoids in 9 weeks. This is similar to the rate of reproductive development reported in earlier studies with $R$. speratus [14].

Egg-laying periods in ergatoids which were fed filter paper with $0.05 \%$ norharmane were shortened by 2 weeks in comparison with the blank test (a filter paper without norharmane) (Table 3). Moreover, egg-laying by nymphoids was only observed in a container supplied with a filter paper with $0.10 \%$ norharmane (Table 4). Egg-laying observations in the present study showed the possibility that norharmane could be involved in egg development in ergatoids and nymphoids. Rates of JH synthesis were reported to be related to the number of vitellogenic ovarioles in neotenic reproductives of the termite $R$. flavipes [5], which correspond to ergatoids and nymphoids in the present study. A possible mechanism for norharmane to regulate the $\mathrm{JH}$ synthesis in ergatoids and nymphoids of $R$. speratus may be as follows: 1 ) stimulation of JHEH activity by ingested norharmane, 2) a decrease in JH titer by boosted JHEH activity, and 3) an increase in the rates of $\mathrm{JH}$ synthesis to compensate for low $\mathrm{JH}$ titers. In a variety of insect species, for normal ovarian development, the adult female requires the presence of active corpora allata which secrete $\mathrm{JH}$ [15]. In ergatoids and nymphoids of $R$. speratus, low JH titers caused by JHEH activity, which depends on norharmane, could trigger JH synthesis required for ovarian development.

Eggs from nymphoids kept on filter paper treated with $0.10 \%$ norharmane hatched 4 to 5 weeks after the eggs were laid (Table 4). This observation is consistent with the result of $34.95 \pm 0.12$ days for the mean hatching period of an inseminated egg in $R$. speratus [16]. The result showed that ingested norharmane did not affect the hatching period of eggs.

\section{ACKNOWLEDGEMENTS}

We gratefully thank Dr Osamu Kitade (Ibaraki University) for advice on identification of a nymphoid of $R$. speratus and anonymous reviewers for their helpful criticism.

\section{REFERENCES}

[1] Zhou X, Oi FM, Scharf ME. Social exploitation of hexamerin: RNAi reveals a major caste-regulatory factor in termites. Proc Natl Acad Sci 2006; 103: 4499-4504.
[2] Takematsu Y. Biometric study on the development of the castes in Reticulitermes speratus (Isoptera, Rhinotermitidae). Jpn J Ent 1992; 60: 67-76.

[3] Lüscher M. Hormonal control of caste differentiation in termites. Ann NY Acad Sci 1960; 89: 549-563.

[4] Yin CM, Gillot C. Endocrine control of caste differentiation in Zootermopsis angusticollis Hagen (Isoptera). Can J Zool 1975; 53: 1701-1708.

[5] Elliott KL, Stay B. Juvenile hormone synthesis as related to egg development in neotenic reproductives of the termite Reticulitermes flavipes, with observations on urates in the fat body. Gen Comp Endocrinol 2007; 152: 102-110.

[6] Miura T, Koshikawa S, Matsumoto T. Winged presoldiers induced by a juvenile hormone analog in Zootermopsis nevadensis: implications for plasticity and evolution of caste differentiation in termites. J Morphol 2003; 257: 22-32.

[7] Itakura S, Kawabata S, Tanaka H, Enoki A. Effect of norharmane on juvenile hormone epoxide hydrolase activity in vitro in the lower termite, Reticulitermes speratus. J Insect Sci 2008; 8:13 $11 \mathrm{pp}$.

[8] Siderhurst MS, James DM, Rithner CD, Dick DL, Bjostad LB. Isolation and characterization of norharmane from Reticulitermes termites (Isoptera: Rhinotermitidae). J Econ Entomol 2005; 98: 1669-1678.

[9] Siderhurst MS, James DM, Blunt TD, Bjostad LB. Antimicrobial activity of the termite (Isoptera) alkaloid norharmane against the entomopathogenic fungus Metarhizium anisopliae. Sociobiology 2005; 46: 563-77.

[10] Siderhurst MS, James DM, Bjostad LB. Ultraviolet light induced autophototoxicity and negative phototaxis in Reticulitermes termites (Isoptera: Rhinotermitidae). Sociobiology 2006; 48: 27-49.

[11] Miyata H, Furuichi H, Kitade O. Patterns of neotenic differentiation in a subterranean termite, Reticulitermes speratus (Isoptera: Rhinotermitidae). Entomol Sci 2004; 7: 309-314.

[12] Share MR, Roe RM. A partition assay for the simultaneous determination of insect juvenile hormone esterase and epoxide hydrolase activity. Anal Biochem 1988; 169: 81-88.

[13] Hammock BD, Abdel-Aal YAI, Mullin CA, Hanzlik TN, Roe RM. Substituted thiotrifluoropropanones as potent selective inhibitors of juvenile hormone esterase. Pestic Biochem Physiol 1984; 22: 209223.

[14] Watanabe H, Noda H. Small-scale rearing of a subterranean termite, Reticulitermes speratus (Isoptera: Rhinotermitidae). Appl Entomol Zool 1991; 26: 418-420.

[15] Nijhout MM, Riddiford LM. The control of egg maturation by juvenile hormone in the tobacco hornworm moth, Manduca sexta. Biol Bull 1974; 146: 377-392.

[16] Matsuura K, Kobayashi N. Size, hatching rate, and hatching period of sexually and asexually produced eggs in the facultatively parthenogenetic termite Reticulitermes speratus (Isoptera: Rhinotermitidae). Appl Entomol Zool 2007; 42: 241-246. 